Feri Yudianto, 2016. Respon Pertumbuhan dan Hasil Kacang Hijau (Vigna radiata L.) terhadap Berbagai Dosis Pupuk Nitrogen dan Jarak Tanam. Journal Viabel Pertanian. (2016), 10(2) 42-50

\title{
RESPON PERTUMBUHAN DAN HASIL KACANG HIJAU (Vigna radiata L.) TERHADAP BERBAGAI DOSIS PUPUK NITROGEN DAN JARAK TANAM
}

\author{
Feri Yudianto \\ Jurusan Agroteknologi Fakultas Pertanian Universitas Islam Balitar Blitar
}

\begin{abstract}
ABSTRAK
This research intent 1) To know influence of type interaction manures nitrogen with distance plants out to growth and green bean plant result, 2 ) To know difference influence manure nitrogens to growth and green bean results, 3 ) To know distance purpose influences plant out to growth and green bean results. This research is done by use of agglomerate Random Design one was arranged by ala Factorial (RACK) with 2 factors, first factor which is nitrogenic manure dose urea $(N)$ one consist 3 levels which is N1 (N $100 \mathrm{~kg} / \mathrm{ha}), \mathrm{N} 2(\mathrm{~N} 150$ $\mathrm{kg} / \mathrm{ha}$ ) and N3 (N $200 \mathrm{~kg} / \mathrm{ha})$. Second factor which is implant distance (J. ) one consists 2 levels which is $J 1$ (30x20) and J2 (30x30). Observed parameter high cover plant, total productive branch, wight grades about plant upon harvests. dianalisis's data by use of analisis manner (Anova), if ascendant drawned out by DMRT'S quiz 5\%. Result observationaling to point out that: 1 ). Dosed application manures urea's nitrogen $200 \mathrm{~kg} / \mathrm{ha}$ give influence besting to growth and green bean plant results. 2 ). Distance plants out not give influence besting to growth and green bean plant result, but upon crop gives influence besting to growth and green bean plant result.
\end{abstract}

Keyword: Dose of nitrogen fertilizer, plant spacing, growth and yield of green beans.

\section{PENDAHULUAN}

Kacang hijau adalah sejenis tanaman budidaya dan palawija yang dikenal luas di daerah tropika. Tumbuhan yang termasuk suku polong-polongan (Fabaceae) ini memiliki banyak manfaat dalam kehidupan sehari-hari sebagai sumber bahan pangan berprotein nabati tinggi. Kacang hijau di Indonesia menempati urutan ketiga terpenting sebagai tanaman pangan legum, setelah kedelai dan kacang tanah. Agar dapat melakukan budidaya kacang hiaju dengan baik, maka perlu dilakukan persiapan semaksimal mungkin salah satu melalui penggunaan benih yang baik. Ketersediaan benih yang baik terkadang kurang sesuai dengan kebutuhan pasar, karena benih yang telah dipanen masih dapat di serang peh berbagai hama dan penyakit. Untuk itu perlu dilakukan pengendalian yang cepat dan tepat agar produksi kacang hijau dapat maksimal. (Soeprapto, 2000).

Pada umumnya daerah tersebut tingkat kesuburan tanahnya mulai menurun, sehingga pemberian pupuk organik sangat penting untuk meningkatkan kesuburan tanah. Usaha untuk meningkatkan produksi kacang hijau dapat ditempuh melalui perbaikan teknik budidaya diantaranya melalui pengaturan jarak tanam dan pemupukan kalium. Seperti tanaman kacang-kacangan lain, tanaman kacang hijau dapat mengikat $\mathrm{N}$ dari udara sehingga kebutuhan akan hara nitrogen bagi tanaman dapat dipenuhi (Anonim, 1983).

Pada umumnya daerah tersebut tingkat kesuburan tanahnya mulai menurun, sehingga pemberian pupuk organik sangat penting untuk meningkatkan kesuburan tanah. Usaha untuk 
Feri Yudianto, 2016. Respon Pertumbuhan dan Hasil Kacang Hijau (Vigna radiata L.) terhadap Berbagai Dosis Pupuk Nitrogen dan Jarak Tanam. Journal Viabel Pertanian. (2016), 10(2) 42-50

meningkatkan produksi kacang hijau dapat ditempuh melalui perbaikan tehnik budidaya diantaranya melalui pengaturan jarak tanam dan pemupukan kalium. Seperti tanaman kacang-kacangan lain, tanaman kacang hijau dapat mengikat $\mathrm{N}$ dari udara sehingga kebutuhan akan hara nitrogen bagi tanaman dapat dipenuhi (Anonim, 1983). Disamping itu dengan pengaturan jarak tanam diharapkan berpengaruh terhadap peningkatan produksi kacang hijau. Pemakaian jarak tanam $30 \mathrm{~cm}$ x $20 \mathrm{~cm}$ dengan 2 biji per lubang menghasilkan produksi yang optimal/ha biji kering Beberapa tipe jarak tanam yang dipakai antara lain : $30 \mathrm{~cm} \times 30 \mathrm{~cm}, 30 \mathrm{~cm} \times 20 \mathrm{~cm}$ dan sebagainya. Pada jarak tanam yang lebar pertumbuhan lebih cepat dibandingkan pada jarak tanam yang sempit. Hal ini disebabkan karena terjadi perebutan unsur hara dalam tanah dan sinar matahari dalam proses fotosintesis.

(Ir. Suprapto HS, Ir. Tatang Sutarman, 1986)

\section{Waktu Dan Tempat}

\section{METODE PENELITIAN}

Penelitian dilakukuan pada bulan 01 juni - 01 september 2016. Tempat penelitian di Desa Margomulyo Kec. Panggungrejo Kab. Blitar.

\section{Alat Dan Bahan}

Alat yang digunakan adalah cangkul untuk menggemburkan tanah dan membersihkan lahan, handsprayer untuk menyemprot pupuk nitrogen ketanaman, penggaris untuk mengukur tinngi tanaman, lebar daun, dan panjang daun, alat tulis.Bahan yang digunakan pada penelitian ini adalah benih kacang hijau, pupuk nitrogen (pupuk urea) dan jarak tanam

\section{Rancangan Percobaan}

Penelitian ini menggunakan metode rancangan acak kelompok ( RAK) yang disusun secara faktorial dengan tiga kali ulangan.

Adapun faktor dan perlakuan sebagaiberikut :

Faktor 1: Pupuk nitrogen ( urea )

$\mathrm{N} 1: 100 \mathrm{~kg} / \mathrm{ha}$

$\mathrm{N} 2: 150 \mathrm{~kg} / \mathrm{ha}$

$\mathrm{N} 3: 200 \mathrm{~kg} / \mathrm{ha}$

Faktor $2:$ Jarak tanam

$\mathrm{J} 1: 30 \times 20 \mathrm{~cm}$

$\mathrm{J} 2: 30 \times 30 \mathrm{~cm}$

Sehingga diperoleh 6 kombinasi perlakuan dan masing-masing perlakuan diulang tiga kali ulangan. Areal percobaan dibagi menjadi 3 kelompok, masing-masing kelompok terdiri dari 6 plot, masing-masing plot terdiri dari 25 tanaman.

\section{Variabel Pengamatan}

Variabel yang diamati meliputi : tinggi tanaman, jumlah cabang produktif, dan bobot kering biji buah per tanaman.

\section{Analisis Data}

Data hasil pengamatan dianalisis dengan menggunakan uji $\mathrm{F}$ pada taraf nyata 5\%. Beda nyata antar perlakuan diuji lanjut dengan Uji Beda Nyata Jujur (BNJ) pada taraf nyata.

\section{Tinggi Tanaman}

\section{HASIL DAN PEMBAHASAN}

Berdasarkan hasil analisis sidik ragam anova $5 \%$ terdapat interaksi antara dosis pupuk nitrogen urea (N) dan jarak tanam (J) tidak berpengaruh nyata terhadap tinggi tanaman kacang hijau pada semua umur pengamatan 14, 28, 42 dan 56 HST. Dosis pupuk nitrogen urea $(\mathrm{N})$ memberi pengaruh nyata pada umur 42 dan 56 HST, tetapi tidak berpengaruh nyata pada umur 14 dan 28 HST. Pada perlakuan jarak tanam (J) tidak pengaruh nyata pada semua umur pengamatan 14, 28, 42 dan 56 HST

Tabel 1.Dosis pupuk nitrogen $(\mathrm{N})$ dan jarak tanam $(\mathrm{J})$ terhadap tinggi tanaman kacang hijau pada berbagai umur pengamatan. 
Feri Yudianto, 2016. Respon Pertumbuhan dan Hasil Kacang Hijau (Vigna radiata L.) terhadap Berbagai Dosis Pupuk Nitrogen dan Jarak Tanam. Journal Viabel Pertanian. (2016), 10(2) 42-50

\begin{tabular}{lllll}
\hline \multirow{2}{*}{ Perlakuan } & \multicolumn{2}{l}{ Tinggi Tanaman (cm) } & \\
& $14 \mathrm{HST}$ & $28 \mathrm{HST}$ & $42 \mathrm{HST}$ & $56 \mathrm{HST}$ \\
\hline Pupuk Nitrogen (N) & & & \\
N1 (N 100 kg/ha) & $19.68 \mathrm{a}$ & $39.64 \mathrm{a}$ & $59.11 \mathrm{a}$ & $79.68 \mathrm{a}$ \\
N2 (N 150 kg/ha) & $19.87 \mathrm{a}$ & $40.58 \mathrm{a}$ & $61.10 \mathrm{~b}$ & $81.45 \mathrm{~b}$ \\
N3 (N 200 kg/ha) & $19.42 \mathrm{a}$ & $38.88 \mathrm{a}$ & $61.84 \mathrm{~b}$ & $80.45 \mathrm{a}$ \\
Jarak Tanam $(\mathbf{J})$ & & & & \\
J1 (30x20) & $19.30 \mathrm{a}$ & $39.45 \mathrm{a}$ & $60.21 \mathrm{a}$ & $80.30 \mathrm{a}$ \\
J2 (30x30) & $19.66 \mathrm{a}$ & $39.42 \mathrm{a}$ & $60.30 \mathrm{a}$ & $80.31 \mathrm{a}$ \\
\hline Duncan 5\% & $\mathbf{2 . 3 0 0}$ & $\mathbf{2 . 2 5 7}$ & $\mathbf{1 . 1 7 6}$ & $\mathbf{0 . 6 4 0}$ \\
\hline
\end{tabular}

Keterangan : Angka-angka yang diikuti dengan huruf yang sama pada baris dan kolom yang sama tidak berbeda nyata pada uji Duncan $(\alpha=0,05)$.

Pada Tabel 1 ditunjukan bahwa pemberian dosis pupuk nitrogen urea $(\mathrm{N})$ pada umur 14 dan 28 HST tidak memberi pengaruh nyata tinggi tanaman. Pada umur pengamatan 42 HST hasil rata-rata tinggi tanaman tertinggi ditunjukan oleh perlakuan N3 (N $200 \mathrm{~kg} / \mathrm{ha})$ yang tidak berbeda dengan N2 (N $150 \mathrm{~kg} / \mathrm{ha}$ ). Sedangkan umur pengamatan 56 HST tinggi tanaman tertinggi ditunjukan oleh perlakuan $\mathrm{N} 2(\mathrm{~N} 150 \mathrm{~kg} / \mathrm{ha})$.

Pada perlakuan jarak tanam J1 (30x20) dan J2 (30x30) menghasilkan nilai rata-rata tinggi tanaman yang tidak berbeda nyata pada semua umur pengamatan.

\section{Jumlah Cabang Produktif}

Berdasarkan hasil analisis sidik ragam anova $5 \%$ terdapat interaksi antara dosis pupuk nitrogen urea $(\mathrm{N})$ dan jarak tanam $(\mathrm{J})$ tidak berpengaruh nyata terhadap jumlah cabang produktif kacang hijau pada semua umur pengamatan 28, 42 dan 56 HST.

Dosis pupuk nitrogen urea $(\mathrm{N})$ memberi pengaruh nyata pada umur 42 dan 56 HST, tetapi tidak berpengaruh nyata pada umur 28 HST. Pada perlakuan jarak tanam tidak pengaruh nyata pada semua umur pengamatan 28,42 dan $56 \mathrm{HST}$.

Tabel 2.pengaruh dosis pupuk nitrogen urea $(\mathrm{N})$ dan jarak tanam $(\mathrm{J})$ terhadap jumlah cabang produktif kacang hijau pada berbagai umur pengamatan

\begin{tabular}{llll}
\hline \multirow{2}{*}{ Perlakuan } & \multicolumn{2}{l}{ Jumlah Cabang Produktif } & \\
& 28 HST & 42 HST & $56 \mathrm{HST}$ \\
\hline Pupuk Nitrogen (N) & & & \\
N1 (N 100 kg/ha) & $1.77 \mathrm{a}$ & $3.82 \mathrm{a}$ & $4.50 \mathrm{a}$ \\
N2 (N 150 kg/ha) & $1.67 \mathrm{a}$ & $3.86 \mathrm{~b}$ & $4.67 \mathrm{~b}$ \\
N3 (N 200 kg/ha) & $1.84 \mathrm{a}$ & $3.85 \mathrm{a}$ & $4.75 \mathrm{~b}$ \\
Jarak Tanam (J) & & & \\
J1 (30x20) & $1.75 \mathrm{a}$ & $3.83 \mathrm{a}$ & $4.53 \mathrm{ab}$ \\
J2 (30x30) & $1.71 \mathrm{a}$ & $3.83 \mathrm{a}$ & $4.58 \mathrm{a}$ \\
\hline Duncan 5\% & $\mathbf{0 . 0 7 4}$ & $\mathbf{0 . 0 6 2}$ & $\mathbf{0 . 0 1 1}$ \\
\hline
\end{tabular}

Keterangan : Angka-angka yang diikuti dengan huruf yang sama pada baris dan kolom yang sama tidak berbeda nyata pada uji Duncan $(\alpha=0,05)$.

Pada Tabel 2 ditunjukan bahwa pemberian dosis pupuk nitrogen urea (N) pada umur 28 HST tidak memberi pengaruh nyata jumlah cabang produktif. Pada umur pengamatan 56 HST hasil rata-rata 
Feri Yudianto, 2016. Respon Pertumbuhan dan Hasil Kacang Hijau (Vigna radiata L.) terhadap Berbagai Dosis Pupuk Nitrogen dan Jarak Tanam. Journal Viabel Pertanian. (2016), 10(2) 42-50

jumlah cabang produktif tertinggi ditunjukan pada perlakuan N3 (N $200 \mathrm{~kg} / \mathrm{ha})$. Hasil terendah ditunjukkan oleh perlakuan N1 (N $100 \mathrm{~kg} / \mathrm{ha}$ ).

Pada perlakuan jarak tanam J1 (30x20) dan J2 (30x30) menghasilkan nilai rata-rata jumlah cabang produktif yang tidak berbeda nyata pada semua umur pengamatan.

\section{Bobot Kering Biji Pertanaman Pada Saat Panen}

Berdasarkan hasil analisis sidik ragam anova $5 \%$ terdapat interaksi antara dosis pupuk nitrogen urea $(\mathrm{N})$ dan jarak tanam $(\mathrm{J})$ tidak berpengaruh nyata terhadap bobot kering biji pertanaman kacang hijau pada saat panen.

Dosis pupuk nitrogen urea $(\mathrm{N})$ tidak memberi pengaruh nyata pada saat panen. Pada perlakuan jarak tanam $(\mathrm{J})$ memberikan pengaruh nyata terhadap berat kering pada saat panen.

Tabel 3.pengaruh dosis pupuk nitrogen urea $(\mathrm{N})$ dan jarak tanam $(\mathrm{J})$ terhadap bobot kering kacang hijau pada saat panen

\begin{tabular}{ll}
\hline Perlakuan & Bobot Kering Biji Pertanaman \\
\hline Dosis Pupuk Nitrogen & \\
N1 (N $100 \mathrm{~kg} / \mathrm{ha})$ & $2.61 \mathrm{a}$ \\
$\mathrm{N} 2(\mathrm{~N} 150 \mathrm{~kg} / \mathrm{ha})$ & $2.59 \mathrm{a}$ \\
$\mathrm{N} 3(\mathrm{~N} 200 \mathrm{~kg} / \mathrm{ha})$ & $2.66 \mathrm{a}$ \\
Jarak Tanam & \\
$\mathrm{J} 1(30 \mathrm{x} 20)$ & $2.18 \mathrm{a}$ \\
$\mathrm{J} 2(30 \mathrm{x} 30)$ & $2.88 \mathrm{~b}$ \\
\hline Duncan 5\% & $\mathbf{0 . 0 3}$ \\
\hline
\end{tabular}

Keterangan : Angka-angka yang diikuti dengan huruf yang sama pada baris dan kolom yang sama tidak berbeda nyata pada uji Duncan $(\alpha=0,05)$.

Pada Tabel 3 ditunjukan bahwa pemberian dosis pupuk nitrogen urea $(\mathrm{N})$ pada tidak memberi pengaruh nyata pada saat panen. Hasil rata-rata bobot kering tertinggi ditunjukan pada perlakuan N3 (N 200 $\mathrm{kg} / \mathrm{ha}$ ). Hasil terendah ditunjukkan oleh perlakuan N1 (N $100 \mathrm{~kg} / \mathrm{ha})$

Pada perlakuan jarak tanam J1 (30x20) dan J2 (30x30) menghasilkan nilai rata-rata bobot kering biji memberi pengaruh nyata pada saat panen

\section{DAFTAR PUSTAKA}

Allard, R.W., 1992. Pemuliaan Tanaman. Jilid 2. Penerjemah Manna.

Lembaga Pusat Penelitian Bogor. 1988. Kalium dan Tanaman Pangan Problem dan Prospek.

Balitkabi. 2004. Balai Penelitian Tanaman Kacang-kacangan dan Umbi-umbian. PenerbitPT Rineka, Cipta, Jakarta.

Balitkabi. 2005. Teknologi produksi kacang-kacangan dan umbi-umbian. Balai penelitian Tanaman Kacang-kacangan dan Umbi-umbian.

Effendi, S., 1976. Pola Bertanam (crop-ping system) Usaha Untuk Sta-bilisasi 
Feri Yudianto, 2016. Respon Pertumbuhan dan Hasil Kacang Hijau (Vigna radiata L.) terhadap Berbagai Dosis Pupuk Nitrogen dan Jarak Tanam. Journal Viabel Pertanian. (2016), 10(2) 42-50

Hartanto, 2005, Dasar-dasar Agronomi I. Departemen Pendidikan Dan Kebudayaan RI. Universitas Surakarta.

Hilman, Y. A. Kasno, dan N. Saleh. 2004. Kacang-kacangan dan umbi-umbian: Kontribusi terhadap ketahanan pangan dan perkembangan teknologinya. Dalam Makarim, et al. (penyunting). Inovasi Pertanian Tanaman Pangan. Puslitbangtan Bogor

Lingga, P. 1996. Petunjuk Penggunaan Pupuk. PT. Penebar Swadaya. Jakarta. 55 h.

Nonomura, A.M., and A.A. Benson. 1992. The Path of Carbon in Photosynthesis; Improved Crop Yields With Methanol. Proccedings of The National Academy

Notohadiprawiro, T. 1998. Tanah dan Lingkungan. Dirjen Pendidikan Tinggi. Depdikbud. Jakarta.

Nurdin, F. 1994. Kacang Hijau di Sumatera Barat: Budidaya, Hama, dan pengendaliannya di tingkat petani. Risalah Seminar Balittan Sukarami. Vol. III. Balittan Sukarami

Purwono dan Hartono, R. 2005. Kacang hijau. Penebar Swadaya. Jakarta.

Rukmana, R., 1997. Kacang Hijau, Budidaya dan Pasca Panen. Kanisius, Yogyakarta

Roswarkam, A. dan Yuwono, N.W. 2002. Ilmu kesuburan tanah. Kanisius. Yogyakarta.

Tatang Sutarman, 1986, Budidaya Kacang Hijau

Samuel, 1974. Ilmu Cuaca dan Suhu

Sarief, E. S. 1986. Kesuburan dan pemupukan Tanah Pertanian. Pustaka Buana, Bandung.

Sitompul, S.M, dan B. Guritno., 1995. Analisis Pertumbuhan 8 Tanaman. Gadjah Mada University Press Yogyakarta

Syam, R. 1992. Pengaruh Konsentrasi Pupuk Gandasil dan Jarak Tanam Terhadap Pertumbuhan dan Produksi Kacang Hijau Varietas Parkit. Fakultas Pertanian Universitas Muhamadiyah Malang. $67 \mathrm{~h}$.

Soeprapto. 2000. Bertanam Kacang Hijau. Penebar Swadaya. Anggota IKAPI. $33 \mathrm{P}$.

Sunantara, I.M.M. 2000. Teknik produksi benih kacang hijau. No. Agdex: 142/35.No.Seri:03/Tanaman/2000/September 2000.Instalasi Penelitian dan Pengkajian

Tim Prima Tani. 2006. Inovasi Teknologi Unggulan Tanaman Pangan Berbasis Agroekosistem Mendukung Prima Tani.Puslitbangtan Bogor. 